\title{
Cardiovascular Risk Behavior Amongst Adolescents of Lekhnath Muncipality of Kaski district, Nepal
}

\author{
Ghimire HP ${ }^{1}$, Dhungana $A^{2}$ \\ ${ }^{1}$ Assistant Professor, ${ }^{2}$ Lecturer, Department of Community Medicine, \\ Gandaki Medical College \& Teaching Hospital, Pokhara, Nepal
}

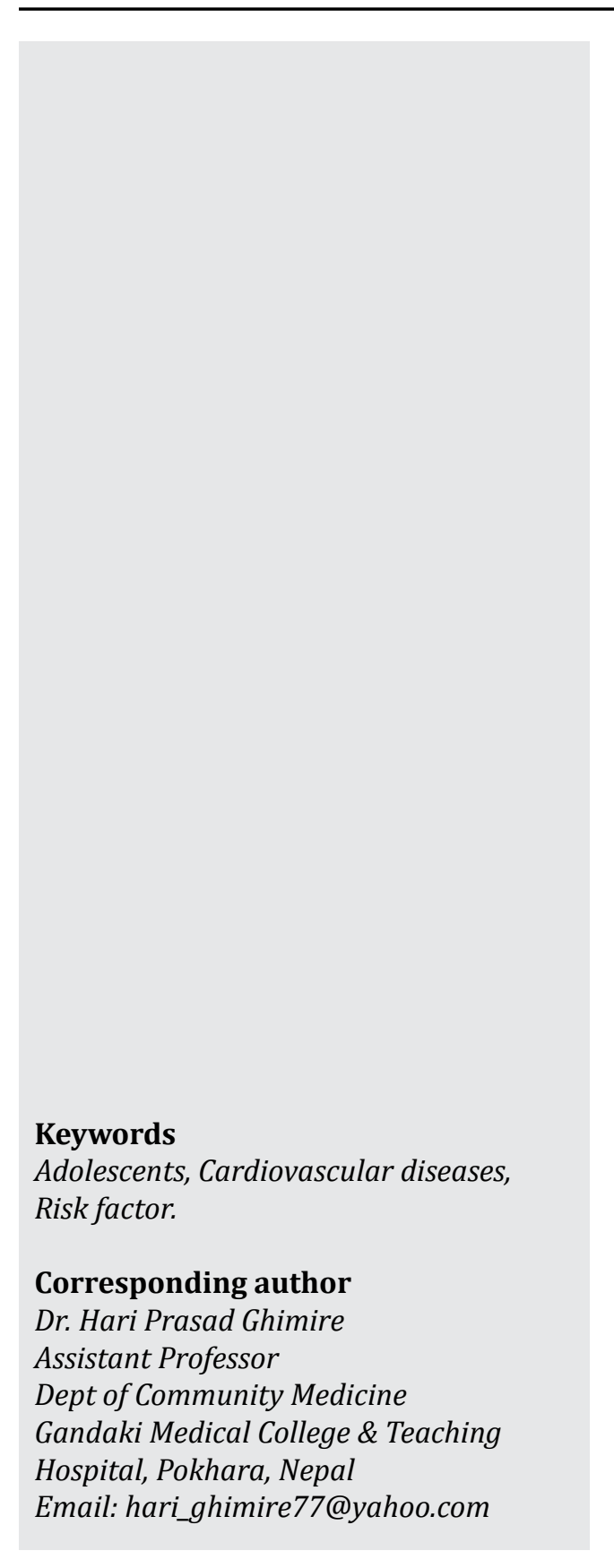

\section{INTRODUCTION}

Cardiovascular diseases (CVD) are the leading causes of morbidity and mortality worldwide ${ }^{1}$. Low and middle income countries contribute significantly to the global burden of CVD accounting for $78 \%$ of all deaths pal.

\begin{abstract}
Background: Life style related behavioral risk factors are mainly implicated for increase burden of cardiovascular diseases. Research related to these risk behaviors especially among adolescents is essential considering their role as future citizens of the country.
\end{abstract}

Objectives: The study aimed to evaluate the burden of cardiovascular risk behavior amongst the adolescents of Kaski district, Lekhnath Ne-

\begin{abstract}
Methods: A cross sectional study was carried out among the adolescents of Lekhnath Muncipality Kaski District. Total 350 participants from five different schools from Lekhnath Muncipality took part in the study and the sampling technique was simple random method by using a random number table. Self administered questionnaires were used to collect information on identification of risk behaviors.
\end{abstract}

Results: Descriptive statistics and Chi square test were computed. Out of 350 adolescents 175 males and remaining 175 females were interviewed. Alcohol and tobacco consumption were more amongst males whereas fast food and soft drinks were more amongst the females. Nearly $40 \%$ of the adolescents were not involved in physical activity. Tobacco and alcohol consumption was $26 \%$ and $16 \%$ respectively, which was higher amongst the late adolescents group studying in the $11^{\text {th }}$ and $12^{\text {th }}$ standard. In this study fruits and vegetables consumption was very less only $42 \%$ whereas soft drinks and fast food consumption was more $83 \%$ which shows that the adolescents are not aware about their food habits. Some participants did not consume fruits due to low purchasing power to buy fruits. Adolescence is a period of experimentation and so some participants told that they have just started taking alcohol and also started consuming tobacco for fun and were not aware that it was cardiovascular risk behavior.

Conclusions: The adolescents had a high burden of cardiovascular risk behavior and if immediate intervention is not done to reduce these high risk behaviors many may be vulnerable to cardio vascular diseases in the future.

attributable to this cause ${ }^{2}$. Countries such as India, Pakistan, Bangladesh, Sri Lanka and Nepal comprising of 20 percent of the world's population have a very high prevalence of $\mathrm{CVD}^{3}$. In Nepal, few community based studies have suggested a very high prevalence risk factors of CVD in the general population that includes diabetes 
mellitus, hypertension, overweight, inadequate physical activity, and tobacco consumption ${ }^{4,5}$. People dying of CVD have major modifiable risk factors which include high blood pressure, abnormal lipids, tobacco use, excessive alcohol use, physical inactivity, obesity, unhealthy diet and diabetes mellitus ${ }^{6-11}$. These lifestyle risk factors which include smoking, tobacco and excessive alcohol use, poor dietary patterns and physical inactivity have been observed in adolescents and adults in both developed and developing countries ${ }^{12-16}$.

\section{METHODS}

\section{Study design, population and sampling}

A cross sectional study was carried out among the adolescents of Lekhnath Muncipality, Kaski District Nepal. Total 350 participants from five different schools from Lekhnath Muncipality took part in the study and the Sampling technique was simple random method by using a random number table. Self administered questionnaire was used to collect information on identification of cardiovascular risk behaviors. Consumption of fruits and vegetables, fast foods, carbonated drinks was assessed for last seven days. Physical activity (which increases heart rate and makes one short of breath for some time) carried out in last week and hours spent in sedentary activity on a typical day was assessed. Students with physical activity of at least $30 \mathrm{~min} /$ day for two or less days in the past week were classified as inactive and for three or more days as active. Consumption of any form of tobacco (smoking/ smokeless) or alcohol in past 30 days was also enquired. Non-responders or participants who choose "don't know" option or those who had a missing response for desired risk factor were excluded from the analysis. All data were analyzed by using software Excel 2010.

Table 1: Consumption of fruits or vegetables in past week among adolescents

\begin{tabular}{cccc}
\hline Class & n & $\begin{array}{c}\text { Fruits or vegetable } \\
\text { consumption three or } \\
\text { more times per/day }\end{array}$ & \\
\hline 7 & 60 & $23(38.3 \%)$ & Chi Square \\
$=5.99$ \\
8 & 78 & $18(23.0 \%)$ & df $=1$ \\
9 & 44 & $12(27.2 \%)$ & P $<0.05$ \\
10 & 30 & $15(50.0 \%)$ & \\
11 & 54 & $30(55.5 \%)$ & \\
12 & 84 & $50(59.5 \%)$ & \\
& $\mathbf{N}=350$ & $\mathbf{1 4 8 ( 4 2 . 2 \% )}$ & \\
\hline
\end{tabular}

Table 2: Soft drinks and fast food consumption in past week among adolescents

\begin{tabular}{cccc}
\hline Class & n & $\begin{array}{c}\text { Soft drinks and fast } \\
\text { food consumption one } \\
\text { or more times a day }\end{array}$ & \\
\hline 7 & 60 & $50(83.3 \%)$ & Chi square \\
$=3.22$ \\
8 & 78 & $62(79.4 \%)$ & $\mathrm{df}=1$ \\
9 & 44 & $37(84.0 \%)$ & $\mathrm{P}<0.05$ \\
10 & 30 & $24(80.0 \%)$ & \\
11 & 54 & $44(81.4 \%)$ & \\
12 & 84 & $74(88.0 \%)$ & \\
& $\mathbf{N}=350$ & $\mathbf{2 9 1 ( 8 3 . 1 \% )}$ & \\
\hline
\end{tabular}

Table 3: Activity pattern among adolescents in past week

\begin{tabular}{cccc}
\hline Class & n & $\begin{array}{c}\text { Physical activity } \\
\text { among adolescents }\end{array}$ & \\
\hline 7 & 60 & $42(70.0 \%)$ & Chi square \\
$=4.78$ \\
8 & 78 & $60(76.9 \%)$ & $\mathrm{df}=1$ \\
9 & 44 & $35(79.5 \%)$ & $\mathrm{P}<0.05$ \\
10 & 30 & $15(50.0 \%)$ & \\
11 & 54 & $20(37.0 \%)$ & \\
12 & 84 & $45(53.5 \%)$ & \\
& $\mathbf{N = 3 5 0}$ & $\mathbf{2 1 7}(\mathbf{6 2 . 0 \%})$ & \\
\hline
\end{tabular}

Table 4: Tobacco use among adolescents in last 30 days

\begin{tabular}{cccc}
\hline Class & n & $\begin{array}{c}\text { Tobacco users among } \\
\text { adolescents }\end{array}$ & \\
\hline 7 & 60 & $1(1.6 \%)$ & Chi square \\
$=3.26$ \\
8 & 78 & $3(3.8 \%)$ & $\mathrm{df}=1$ \\
9 & 44 & $18(40.9 \%)$ & $\mathrm{P}<0.05$ \\
10 & 30 & $16(53.3 \%)$ & \\
11 & 54 & $19(35.1 \%)$ & \\
12 & 84 & $34(40.4 \%)$ & $\mathbf{9 1}(\mathbf{2 6 . 0 \% )}$ \\
& $\mathbf{N = 3 5 0}$ & & \\
\hline
\end{tabular}

Table 5: Alcohol use among adolescents in last 30 days

\begin{tabular}{cccl}
\hline Class & n & $\begin{array}{c}\text { Alcohol users among } \\
\text { adolescents }\end{array}$ & \\
\hline 7 & 60 & $1(1.6 \%)$ & Chi square \\
8 & 78 & $2(2.56 \%)$ & 2.16 \\
9 & 44 & $5(11.3 \%)$ & $\mathrm{df}=1$ \\
10 & 30 & $6(20.0 \%)$ & $\mathrm{P}<0.05$ \\
11 & 54 & $18(33.3 \%)$ & \\
12 & 84 & $24(28.5 \%)$ & \\
& $\mathbf{N = 3 5 0}$ & $\mathbf{5 6 ( 1 6 . 0 \% )}$ & \\
\hline
\end{tabular}




\section{RESULTS}

Out of 350 adolescents 175 males and remaining 175 females were interviewed. Among the 350 adolescents the mean age of the study population was $15.66 \pm 2.22$. Alcohol and tobacco consumption were more amongst males whereas fast food and soft drinks were more amongst the females.

Consumption of fruits and vegetables three or more times a day in the past week was highest 50 (59.5\%) amongst the class of $12^{\text {th }}$ standard and least was consumed by 18 (23\%) amongst the class 8 students as shown in Table 1; Chi Square value 5.99, P value $<0.05$. Soft drinks and fast food consumption one or more times a day in past week was highest $74(88 \%)$ amongst the class of $12^{\text {th }}$ standard followed by $9^{\text {th }}$ class 37 (84\%) and least 62 (79.4\%) amongst the class of 8 as shown in Table 2; Chi square value 3.22 , $\mathrm{P}$ value $<0.05$.

Physical activity amongst students was highly appreciated by the $9^{\text {th }}$ class $35(79.5 \%)$ and least appreciated by $11^{\text {th }}$ standard which was only 20 (37\%) as shown in Table 3; Chi square value 4.78 , P value $<0.05$. Tobacco use among adolescents in last 30 days was high amongst the $10^{\text {th }}$ class $16(53.3 \%)$ and least was amongst the grade 7 students one (1.6\%) as shown in Table 4; Chi Square value 3.26, $P$ value $<0.05$. Alcohol use amongst adolescents in last 30 days was highest amongst the $11^{\text {th }}$ standard 18 (33.3\%) followed by $12^{\text {th }}$ class $24(28.5 \%)$ and least was amongst the grade 7 students which was only one $(1.6 \%)$ as shown in Table 5; Chi Square value 2.16, $\mathrm{P}$ value $<0.05$.

\section{DISCUSSION}

Cardiovascular disease (CVD) is on the increase in developing countries and more prevalent in the working age population resulting in large social and economic burden. The increase in CVD burden in developing countries is largely the result of an increase in the prevalence of CVD risk factors.

People dying of CVD have major modifiable risk factors which include high blood pressure, tobacco use, excessive alcohol use, physical inactivity, obesity, unhealthy diet and diabetes mellitus. Many of these risk factors are caused by unhealthy lifestyle and habits, as such they are sometimes referred to as lifestyle risk factors. These lifestyle risk factors which include smoking tobacco and excessive alcohol use, poor dietary patterns and physical inactivity have been observed in adolescents and adults in both developed and developing countries.

In this study fruits and vegetables consumption was very less only $42 \%$ whereas soft drinks and fast food consumption was more (83\%) which shows that the adolescents are not aware about their food habits. Fruits and vegetables consumption is gradually replaced with fast foods or ready to eat foods as student progress through the college reported by Rustagi et al ${ }^{17}$ which showed similiarity with this study. Some participants did not consume fruits due to low purchasing power to buy fruits. Physical activity was practiced by only $62 \%$ of the participants and most of them were boys. Tobacco and alcohol consumption was $26 \%$ and $16 \%$ respectively, which was higher amongst the late adolescents group studying in the $11^{\text {th }}$ and $12^{\text {th }}$ standard. Similar type of study done amongst the adolescents of Nepalgunj, Manita et $a l^{18}$ shows lower prevalence of consumption of tobacco $8.4 \%$ and alcohol $6.9 \%$ by adolescents. Adolescence is a period of experimentation and so some participants told that they have just started taking alcohol and also started consuming tobacco but were not aware that it was a cardiovascular risk behavior.

Investigating CVD risk factors among adolescents is important because adolescence is a critical temporal window for the development of obesity in adult age. Dietary habits, and risky behaviors, such as smoking and drinking are experimented with and established in childhood and adolescence. Furthermore researchers have advocated that children and adolescent populations should be the target for cardiovascular risk factors prevention programs because lifestyle risk factors are usually learnt and established during this period. CVD prevention program are thus likely to be more effective in this subpopulation. Modifiable risk factors can be prevented, treated and controlled, hence the need for early detection of risk factors and CVD prevention programs so that adolescents adopt healthy behaviors into adulthood.

In conclusion, the presence of cardiovascular risk factors is an important health problem among the adolescents of Lekhnath Muncipality. There is a need for a national program to control cardiovascular risk factors among these adolescents who may be vulnerable to cardiovascular diseases in the future. Promotion of supportive environment for strengthening student-based approaches and strategic delivery of health education is also essential to target these risk behaviors among our future citizens. 


\section{Acknowledgements}

I would like to thank all the students of Lekhnath municipality who participated in this study and the school teachers whose help was highly appreciated

\section{REFERENCES}

1. Murray CJ, Lopez AD. Mortality by cause for eight regions of the world: Global Burden of Disease Study. Lancet. 1997; 349: 1269-76.

2 WHO. The World Health Report 1999. Making a difference. Geneva: World Health Organisation, 1999.

3. Goyal A, Yusuf S. The burden of cardiovascular disease in the Indian subcontinent. Indian J Med Res. 2006; 124: 235.

4. Vaidya A, Pokharel PK, Karki P, Nagesh S. Exploring the iceberg of hypertension: A community based study in an Eastern Nepal town. Kathmandu Univ Med J. 2007; 5(3): 349-59.

5. Vaidya A, Pokharel PK, Nagesh S, Karki P, Kumar S, Majhi S. Association of obesity and physical activity in adult males of Dharan, Nepal. Kathmandu Univ Med J. 2006; 4(2): 192-7.

6. CDC: Heart Disease Risk Factors. www.cdc.gov/Heart Disease/risk factors. Accessed 12 July 2015.

7. World Heart Federation. Cardiovascular disease risk factors. www.world.heart.federation.org. (2012) accessed February 13, 2015.

8. Yusuf S, Hawken S, Ounpuu S, on behalf of the INTERHEART Study Investigators. Effect of potentially modifiable risk factors associated with myocardial infarction in 52 countries (THE INTERHEART STUDY): case-control study. Lancet. 2004; 364: 937-952.

9. Stewart S, Wilkinson D, Becker A, Askew D, Ntyintyane L, McMurray JJ. Mapping the emergence of heart disease in a black urban population in Africa (The Heart of Soweto Study). Int J Cardiol. 2006; 108(1): 101-8.
10. Sliwa K, Wilkinson D, Hansen C, Ntyintyane L, Tibazarwa K, Becker A, Stewart S. Spectrum of heart disease and risk factors in a black urban population in South Africa (The Heart of Soweto Study): A cohort study. Lancet. 2008; 371 (9616): 915-22.

11. Tibazarwa K, Ntyintyane L, Sliwa K, Gerntholtz T, Carrington M, Wilkinson D, Stewart S. A time bomb of cardiovascular risk factors in South Africa: Results from the Heart of Soweto Study "Heart Awareness Days". Int J Cardiol. 2009; 132(2): 233.

12. May AL, Kukina EV, Yoon PW. Prevalence of cardiovascular disease risk factors among US adolescents 1999-2008. Paediatrics. 2012; 129(6): 1035-41. doi: 10.1542/peds.2011-1082.

13. Barret SC, Huffman FG, Johnson P, Campa A, Magnus M, Ragoobirsing D. A cross sectional study of Jamaican adolescents risk for type 2 diabetes and cardiovascular disease risk factors. BMJ Open. 2013; 3(7): e002817.

14. Velasquez-Rodriguez CMI, Velasqez-Villa M, GomezOcampo L, Bermúdez-Cardona J. Abdominal obesity and low physical activity are associated with insulin resistance in overweight adolescents: A crosssectional study. BMC Pediatr. 2014; 14: 258. doi: 10.1186/1471-2431-14-258.

15. Ansa VO, Odigwe CO, Anah MU. Profile of body mass index and obesity in Nigerian children and adolescents. Niger J Med. 2001; 10(2): 78-80.

16. Odunaiya NA, Ayodele AO, Oguntibeju OO. Physical activity levels of Senior Secondary School Studies in Ibadan. W India Med J. 2010; 59(5): 595-34.

17. Rustagi N, Taneja DK, Mishra P, Ingle GK. Cardiovascular risk behavior among students of a Medical College in Delhi. Indian J Community Med. 2011 Jan-March; 36(1): 51-53.

18. Pyakurel M, Ghimire A, Pokhrel P. Cardiovascular risk factors among adolescents of Nepalgunj Municipality in Nepal. Geneva Health Forum. 14/9/2013. 